\section{Facilitating Sound, Cost-Effective Federal Energy Management}

The Federal Government, as the nation's largest energy consumer, has a tremendous opportunity and acknowledged responsibility to lead by example. The U.S. Department of Energy's (DOE's) Federal Energy Management Program (FEMP) plays a critical role in this effort.

FEMP facilitates the Federal Government's implementation of sound, cost-effective energy management and investment practices to enhance the nation's energy security and environmental stewardship. FEMP does this by focusing on the needs of its Federal customers, delivering an array of services across a variety of program areas.

\section{Program Areas}

Complying with energy legislation and regulations: FEMP analyzes Federal energy legislation and regulations to help agencies comply with all applicable requirements. This assistance is delivered through interagency coordination, development of guidance documents, and assistance with annual reporting requirements.

Executive Order (E.O.) 13514, Federal Leadership in Environmental, Energy, and Economic Performance, set greenhouse gas emissions as a unifying priority for Federal energy and environmental management. It requires agencies to inventory and reduce greenhouse gas emissions in addition to other energy and environmental mandates. E.O. 13514 expands upon the energy reduction and environmental performance requirements of E.O. 13423.

Designing, operating, and maintaining high-performance buildings: FEMP helps Federal agencies implement sustainable design practices that incorporate greenhouse gas reduction, energy efficiency, renewable energy, water efficiency technologies, and other sustainable aspects. These practices span new construction, retrofit projects, and operations and maintenance. FEMP services include energy audits, combined heat and power assessments, operations and maintenance assessments, laboratory design protocols, independent evaluations of technologies, advanced metering, and guidance for procuring energy-efficient and renewable energy products.

FEMP's Laboratories for the 21st Century (Labs21) partnership with the U.S. Environmental Protection Agency (EPA) significantly reduces Federal laboratory energy use each year. FEMP also works with industrial facilities to improve energy and water efficiency.

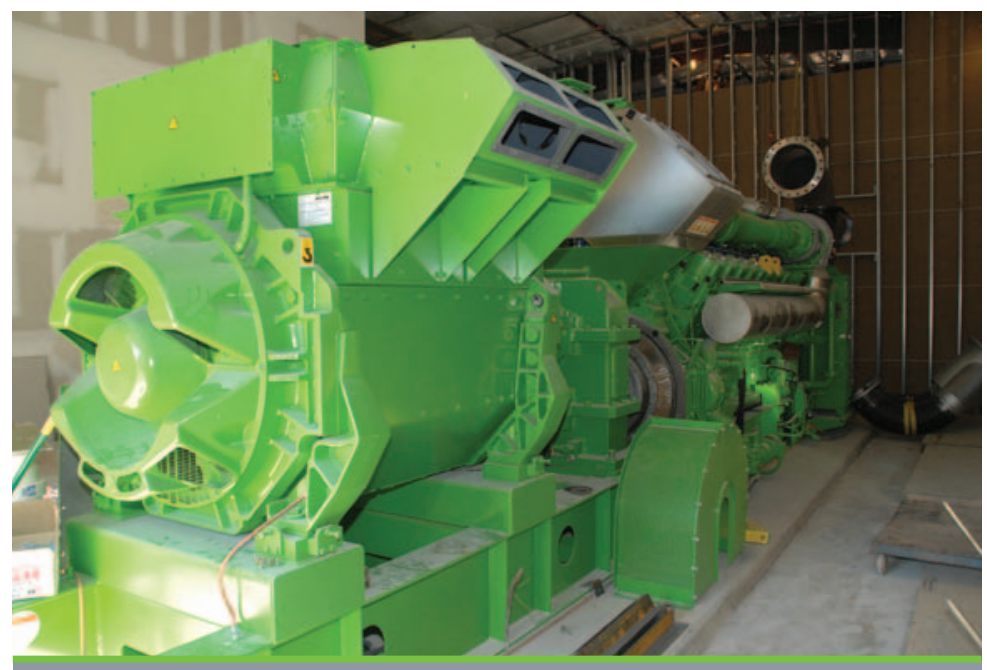

U.S. Marine Corps Logistics Base Albany will use this 1.9 MW methane power generator as part of an ongoing landfill gas project to exceed Federal renewable energy requirements. Photo by Pamela Jackson, United States Marine Corps

FEMP helps facilitate Federal data center energy efficiency. The program develops tools and resources to make data centers more energy efficient, including DOE data centers.

Evaluating and procuring energy-efficient products: The Federal Government can reduce energy consumption and achieve enormous cost savings by purchasing energy-efficient products. FEMP provides guidance through the publishing of purchasing specifications. This guidance includes energy efficiency requirements, purchasing tips, cost data, user information, and calculators that help Federal agencies offset energy consumption costs through energy-efficient product procurement.

Federal buyers are required by the Energy Policy Act (EPAct) of 2005 and other regulations to purchase products that are ENERGY STAR ${ }^{\circledR}$ qualified or FEMP designated for energy efficiency and low standby power. These products are in the upper 25 percent of energy efficiency in their class.

Implementing renewable energy technologies: EPAct 2005 requires Federal agencies to source no less than five percent of total electricity consumed in fiscal years (FY) 2010 through 2012 from renewable energy, increasing to 7.5 percent in FY 2013 and beyond. FEMP assists Federal agencies in developing and implementing clean, secure energy resources to meet this, and other, renewable energy requirements.

By using renewable energy resources, Federal agencies can meet energy management regulations, help conserve our natural resources, and increase the nation's energy independence and security. 
Deploying water efficiency and conservation best practices: Water efficiency and conservation is an integral part of Federal energy and resource management programs. Not only is it a precious natural resource, but water requires significant energy for treatment, pumping, heating, and processing.

\section{E.O. 13514 and E.O. 13423 contain} significant water reduction mandates, requiring Federal agencies to reduce water consumption intensity two percent annually through FY 2015-or 16 percent by FY 2015 - helps agencies manage water efficiency and conservation efforts through regulatory guidance, interagency coordination, best management practices, and other resources.

\section{Measuring and abating greenhouse} gas emissions: Operating more than 500,000 buildings and an immense vehicle fleet, the Federal Government is the nation's largest energy consumer and greenhouse gas emitter-accounting for 1.6 percent of total U.S. energy consumption. This footprint opens an opportunity for the Federal Government to mitigate climate change by reducing greenhouse gas emissions.

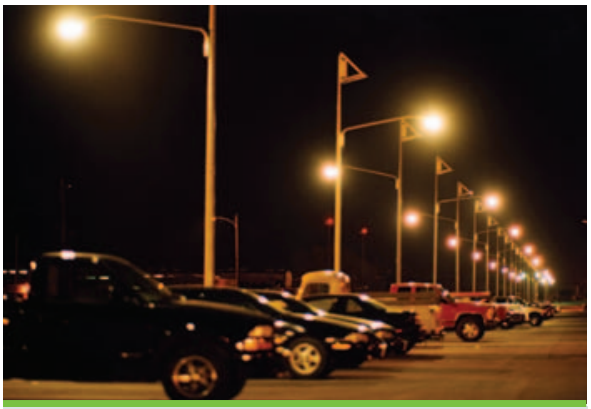

Photovoltaic-powered lights are installed in several parking lots at Fort Hood, Texas, in the largest lighting project of this kind in America. Photo from Solar Outdoor Lighting, NREL/PIX 07839
Complying with E.O. 13514 demands a transformative shift in the way the Federal Government operates, necessitating a deliberate planning process for managing greenhouse gases. FEMP offers greenhouse gas management and abatement services to help Federal agencies meet the goals and requirements of E.O. 13514 and other regulations.

Managing energy-efficient and alternative-fuel vehicle fleets: The Federal fleet consists of approximately 650,000 domestic vehicles. While 25 percent are alternative-fuel vehicles, legislation mandates further reductions in fleet petroleum use through energy-efficient and alternative-fuel vehicles.

FEMP provides guidance on and assistance for implementing and managing energy-efficient and alternative-fuel vehicle fleets. This includes helping Federal agencies meet fleet management requirements, such as reducing petroleum consumption by two percent per year through FY 2020 relative to a FY 2005 baseline and increasing alternative fuel use by 10 percent per year relative to the previous year through 2015 .

Assisting energy project funding and contracting: FEMP supports Federal agencies through assistance in identifying, obtaining, and implementing project funding. These funding tools include energy savings performance contracts (ESPCs), utility energy service contracts (UESCs), power purchase agreements (PPAs), and various Federal and state energy incentives programs.

With assistance from FEMP, the Federal Government's energy management commitment has accelerated and grown in recent years. Federal ESPCs facilitated by DOE now exceed $\$ 2.3$ billion.

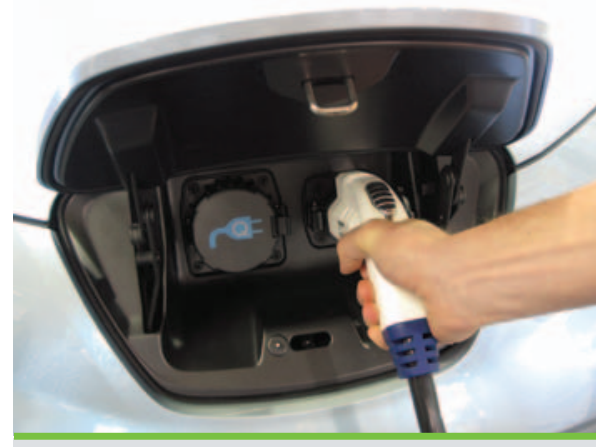

FEMP technical assistance and resources help Federal agencies optimize vehicle fleet inventories with alternative-fuel, hybrid, and electric vehicles. Photo by Andrew Hudgins, NREL/PIX 17634

Training, communicating, and awarding energy management: Federal agencies learn to implement energy-saving strategies, gain recognition for outstanding achievements, and keep current on the Federal Government's progress in meeting energy management goals through FEMP training, services, and outreach.

FEMP services include the FEMP Focus newsletter, the FEMP website, You Have the Power awareness campaigns, online and in-person training, and the annual GovEnergy conference. Recognition programs, including the Federal Energy and Water Management Awards, have honored thousands of Federal employees for outstanding initiative, perseverance, and creativity.

\section{Learn More}

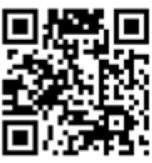

femp.energy.gov Renewable Energy
For more information, visit:

eere.energy.gov

femp.energy.gov

DOE/GO-102012-3543 • March 2012

Printed with a renewable-source ink on paper containing at least $50 \%$ wastepaper, including $10 \%$ post consumer waste. 